\title{
Inovação e mudanças na realidade amazônica: o caso da pesca no município paraense de Vigia de Nazaré
}

José Nazareno Araújo dos Santos - Mestre em Planejamento do Desenvolvimento, pelo NAEA/UFPA é professor substituto da UFPA,

Ana Paula Vidal Bastos - Doutora em Economia pela Universidade de Tsukuba (Japão), professora adjunta da UFPA, lotada no NAEA.

\section{Resumo}

Neste artigo, discute-se a inovação, considerada pela teoria econômica evolucionista como a força motriz do desenvolvimento, por promover um dinamismo econômico capaz de mudar cenários antes sem quaisquer perspectivas de mudança, principalmente em regiões pouco desenvolvidas ou quase sem nenhum grau de desenvolvimento. Constata-se que isso tem acontecido no município de Vigia de Nazaré (PA), especialmente no setor industrial da pesca. A adoção de inovações tem causado transformações no comportamento dos agentes privados e públicos, havendo expectativas positivas quanto ao futuro do setor e do próprio município. Acredita-se que um incremento institucional pode gerar um ambiente favorável à sustentabilidade da atividade e do próprio desenvolvimento local, podendo-se estender o modelo para as esferas estadual e regional.

\section{Palavras-chave}

Inovação; desenvolvimento local; pesca; instituições.

\begin{abstract}
In this article, it is argued innovation, considered for the evolutionist economic theory as the motor force of the development, for promoting economic a dynamism capable to change scenes before without any perspectives change, mainly in regions little developed or almost without no degree of development. It is evidenced that this has happened in the city of Vigia of Nazaré (Pará), especially in the industrial sector of fishes. The adoption of innovations has caused transformations in the behavior of the private and public agents, having positive expectations how much to the future of the sector and the proper city. It is given credit that an institutional increment can generate an environment favorable to the sustainable of the activity and the proper local development, being able itself to extend the model for the spheres state and regional.
\end{abstract}

\section{Keywords}

Innovation; local development; fishery; institutions. 


\section{INTRODUÇÃO}

A importância da adoção de inovações tem sido cada vez mais discutida na literatura econômica, principalmente desde os fins dos anos 70 e o início dos anos 80.

A inovação ganhou destaque no cenário acadêmico, não somente pela sua capacidade de modificar os ambientes nos quais é introduzida, mas principalmente pela sua capacidade de dinamizar e impulsionar o desenvolvimento econômico. Por esse motivo, a inovação é considerada pela teoria econômica evolucionista como a força motriz do desenvolvimento.

É verdadeiro também que, para que o desenvolvimento econômico seja atingido com a adoção de inovações, faz-se necessário que haja uma predisposição local, e isso decorre da formação de um ambiente favorável, onde haja instituições capazes de provocar ou mesmo sustentar ações empreendedoras voltadas para esse fim.

Nesse contexto, as chamadas aglomerações produtivas ganham importância, principalmente quando apresentam tendências inovadoras e são amparadas institucionalmente de forma pró-ativa ou por indução.

A atividade pesqueira do município de Vigia de Nazaré tem na inovação um ponto de atratividade de políticas institucionais direcionadas para a criação de um ambiente favorável ao processo de desenvolvimento do setor. Uma empresa inovadora que tem certo domínio da produção tem assumido a liderança do processo de inovação do setor e, pela postura adotada enquanto agente capitalista, exerce direta influência sobre as instituições que envolvem a atividade.

Por esse motivo, pode-se dizer que a pesca no município de Vigia de Nazaré é um aglomerado produtivo local com caráter inovador (APL(i)), o que permite prever que o ambiente institucional se desenvolverá e potencializará o seu desempenho.

Este artigo procura mostrar tal processo, ressaltando questões que levam a uma reflexão sobre os efeitos causados na dinâmica econômica local, bem como as possibilidades de expandi-lo às esferas estadual e regional. Estruturado de forma a facilitar a compreensão do tema, além desta introdução, o artigo conta com duas seções em que se tecem considerações teóricas sobre a inovação e o desenvolvimento local e uma sobre o setor pesqueiro industrial vigiense. Nas considerações finais, apontam-se as principais questões discutidas.

\section{O PAPEL DA INOVAÇÃO NA CONSTRUÇÃO DO DESENVOLVIMENTO: BREVES REFLEXÕES}

O ponto central de análise da chamada teoria neoschumpeteriana é o papel desempenhado pela inovação (tecnológica) e sua influência na 
dinâmica da atividade econômica capitalista (POSSAS, 1989; ROSENBERG, 2006). De acordo com Nelson e Winter (2005, p. 39) "a preocupação central da teoria evolucionária diz respeito aos processos dinâmicos que determinam conjuntamente os padrões de comportamento da firma e os resultados de mercado ao longo do tempo." Nesse sentido, "se estabelece a busca de uma explicação endógena da inovação, o que implica uma economia da mudança tecnológica ${ }^{1 "}$ (TREVIÑO, 2002, p. 195). O processo de desenvolvimento sustentado pelo avanço tecnológico, portanto, dá-se endogenamente nas estruturas produtivas.

A abordagem neoschumpeteriana, cujas discussões sobre desenvolvimento centram-se nas inovações tecnológicas, busca inspiração nos fundamentos de Schumpeter para a dinâmica capitalista, ao mesmo tempo que tenta mostrar os processos periódicos de transformação econômica e institucional condicionados pela evolução capitalista, em distintos níveis de intensidade e abrangência (POSSAS, 1989), fazendo da firma capitalista a principal unidade de análise de sua elaboração teórica (PAULA et al., 2001).

Pavitt (1984), baseado em investigação empírica e inspirado na concepção evolutiva da mudança econômica, apresenta uma análise das diversas fontes do progresso técnico. Chega à conclusão de que tal progresso deve-se à presença dos distintos setores industriais, bem como às relações existentes internamente entre os setores e entre esses setores e outras instituições. Nesse sentido, o autor apresenta uma taxonomia (classificação) da mudança técnica com basicamente dois elementos, situados em dois extremos: em um pólo, encontram-se as firmas "dominadas por fornecedores", as quais interagem com os setores fornecedores de máquinas e equipamentos, sendo esse processo a fonte da capacidade inovadora dessas firmas; em outro, as firmas baseadas em ciência, em que a participação de instituições de pesquisa, os gastos com pesquisa e desenvolvimento ( $\mathrm{P} \& \mathrm{D}$ ) endogenamente e a aquisição de bens de capital de "fornecedores especializados" são os meios pelos quais se dá o progresso técnico (PAULA et al., 2001; POSSAS, 1989; TAPIA; CAPDEVIELLE, 2002).

Os ganhos obtidos com o progresso técnico pelos agentes produtores podem tornar-se extraordinários em virtude da dificuldade de imitação e de ingresso no mercado, da sustentabilidade do segredo industrial, do patenteamento, do saber fazer e da ocorrência da mudança técnica em economias dinâmicas de aprendizado (TAPIA; CAPDEVIELLE, 2002), o que reforça a condição dinâmica do progresso técnico (POSSAS, 1988), ao mesmo tempo que revela a complexidade do acesso e da difusão da tecnologia apresentada por Rosenberg (1976).

\footnotetext{
${ }^{1}$ se plantea la búsqueda de una explicación endógena de la innovación, lo que implica una economía del cambio tecnológico.
} 
Nelson e Winter (2005) desenvolvem sua análise evolucionista do progresso tecnológico enfocando uma contraposição ao pensamento dominante no que tange ao comportamento da firma e dos mercados. Nesse sentido, apontam dois pontos de ruptura com a teoria ortodoxa, destacando-se a essencialidade do desequilíbrio e das assimetrias no processo de mudança estrutural e de movimento, bem como a presença da incerteza no ambiente de tomada de decisões capitalistas e no esforço inovador das empresas, em virtude principalmente da adesão dos agentes à rotina (POSSAS, 1989; TAPIA; CAPDEVIELLE, 2002).

As rotinas, na visão de Nelson e Winter (2005), são processos importantes para a compreensão da conduta das empresas em um modelo evolutivo, visto que, aliadas a fatores estocásticos, acabam por determinar a própria mudança dessas práticas referentes ao comportamento das empresas. O esforço que as firmas fazem no sentido da inovação, da alteração de suas rotinas a partir delas mesmas é o que os autores denominam processo de busca de oportunidades presentes ou futuras, dado o contexto tecnológico, pois "o resultado das buscas de hoje constitui tanto uma nova tecnologia bem-sucedida como um novo ponto de partida natural para as buscas de amanhã" (NELSON; WINTER, 2005, p. 373).

Esse processo de busca das inovações, quando em interatividade com o de seleção, comporá, em um ambiente competitivo e de mercado, o fundamento do quadro teórico alternativo proposto pela abordagem evolucionista (KUPFER, 1996; POSSAS, 1989) no qual se dá o progresso tecnológico (PAULA et al., 2001).

A busca por inovações é parte de todo processo de progresso tecnológico, que se complementa com o processo de seleção, o qual tem o propósito de validar ou não uma inovação realizada, por meio de uma implementação prática e de uma eventual difusão no mercado e/ ou entre empresas concorrentes.

De acordo com Nelson e Winter (2005), para entender-se melhor as questões ligadas aos efeitos causados pela introdução de inovações em um dado segmento da economia, faz-se necessário distinguir os dois tipos de inovação existentes: algumas podem ser resultantes das atividades de P\&D das firmas no setor em que atuam, "outras podem assumir, em grande parte, a forma de materiais, de componentes ou de equipamentos ofertados pelas firmas fornecedoras" (NELSON; WINTER, 2005, p. 383).

Dosi (1984) apresenta sua contribuição teórica a respeito do progresso da indústria centrado nos fundamentos da chamada "concorrência schumpeteriana", analisando o processo de transformação e de dinâmica no ambiente industrial com base nos padrões da mudança tecnológica.

Tal como Nelson e Winter (2005), o autor em destaque sustenta que o processo de geração e difusão de inovações tecnológicas tem o 
papel de reforçar e mesmo de gestar mecanismos de dinâmica industrial, os quais são oriundos das assimetrias tecnológicas e produtivas. Segundo Dosi (1984), as assimetrias assumem um importante papel no processo da dinâmica industrial, uma vez que provocam uma transformação nos padrões industriais então existentes. É a partir, portanto, da existência de assimetrias que a dinâmica inovadora e industrial tem "sustentabilidade" e continuidade no âmbito industrial.

Isso é, de certo modo, constatado no setor industrial pesqueiro vigiense: apesar de não haver tendências generalizadas de inovação e, portanto, de concorrência mais intensa, a inovação tecnológica contém elementos de base modificadores da estrutura produtiva do setor no local, o que se reflete nos demais locais de atuação das empresas de pesca (em âmbito estadual e regional).

A inovação como ocorre na pesca industrial do Pará e mais especificamente em Vigia de Nazaré, porém, não deixa de aproximar-se da assimetria apresentada por Dosi (1984), pois torna a indústria pesqueira vigiense (por meio de sua empresa líder) uma assimiladora exclusiva dos ganhos oriundos da inovação, até que o mercado selecione e passe a imitar seus métodos produtivos. Nesse sentido, diz-se que a adoção de práticas inovadoras que revolucionam os padrões vigentes coloca o inovador em situação de vantagem competitiva no ambiente de mercado, ampliando e reforçando sua condição de líder, impulsionando a dinâmica econômica.

Entretanto, é importante frisar que o processo de adoção e de desenvolvimento de inovações em regiões periféricas dos grandes centros é limitado e, em alguns aspectos, precário, o que torna mais complexa a internalização desse processo (CROCCO et al., 2006).

\section{A INOVAÇÃO E A INTERAÇÃO COM O AMBIENTE LOCAL NA VISÃO EVOLUCIONISTA}

A inovação, mais precisamente a inovação tecnológica ${ }^{2}$, tem papel precípuo na promoção do desenvolvimento econômico, e a geração e a difusão desse tipo de inovação são sua forma de promoção, que exige acumulação de conhecimento e um ambiente propício para tal (TEECE, 2005). O conhecimento e o aprendizado, portanto, são importantes para a construção de um espaço em que a interação entre os agentes econômicos crie as condições para a promoção da dinâmica tecnológica em termos locais.

Assim sendo, é indispensável considerar a dinâmica territorial (GALVÃO, 2002), que é fundamental para entender a forma que

\footnotetext{
${ }^{2}$ Embora as chamadas inovações de processos, que não necessariamente requerem uma inovação de tecnologias, tenham relevância não desprezível.
} 
assumem certos desdobramentos da adoção de inovações, uma vez que as diferenças socioespaciais são importantes para o desenvolvimento técnico-econômico da atualidade (ALBAGLI; MACIEL, 2004).

Por isso, tem-se discutido mais amplamente o espaço local. Nesse "sistema de interações capaz de potencializar o aprendizado tecnoinovativo e de regular as direções empreendidas pelos agentes" (GALVÃO, 2002, p. 42), torna-se importante considerar a dinâmica interna do local .

Lall (2005), por exemplo, destaca a importância do local no processo de difusão de tecnologias e, por extensão, no próprio desenvolvimento do local. Segundo ele, "a importação de tecnologia não é [...] um substituto para o desenvolvimento de aptidões locais; a eficácia com a qual as tecnologias são utilizadas depende de esforços locais" (LALL, 2005, p. 35). A condução e o comportamento do ambiente local condicionam o desempenho de mecanismos implementadores de inovação, por via de geração ou de difusão.

O local acaba sendo forçado pelo progresso tecnológico a "reagir" às necessidades impostas pela mudança econômica introduzida no âmbito produtivo da economia. A literatura mais recente tem procurado evidenciar a importância da dimensão territorial na relação com os processos inovadores (GALVÃO, 2002).

Nesse sentido Lastres et al. (1999, p. 53) destacam:

O foco de contribuições mais recentes neste sentido, em particular na economia da inovação, reside fundamentalmente na noção de que os processos de geração de conhecimento e inovação são interativos e localizados. Isto é, argumenta-se que a interação criada entre agentes localizados em um mesmo espaço favorece o processo de geração e difusão de inovações.

Lastres et al. (1999) e Crocco et al. (2006) confirmam que o desenvolvimento decorre, não somente da implementação de novos processos de produção, mas também da forma como esses processos serão organizados em um ambiente local.

É então possível fazer uma outra análise das transformações recentes na produção e no território (MARTINS, 2001). O território passa a ser incorporado ao desenvolvimento como elemento importante, porque, de acordo com Martins (2001, p. 49), "possui uma importância fundamental, uma dimensão ativa na constituição e evolução dos processos produtivos". Com efeito, o território pode potencializar a integração e o dinamismo social, reforçando-se assim o desenvolvimento local, cuja importância é destacada pela literatura econômica.

Por isso, o processo de desenvolvimento deve ser feito dentro de limites territoriais que forcem, endogenamente, a criação de inovações 
que permitam um ganho para seus criadores e, ao mesmo tempo, inviabilizem o acesso imediato e em um mesmo grau dos agentes externos. Valorizam-se dessa forma os conhecimentos locais. O conhecimento é fruto do aprendizado, e esse aprendizado, quando realizado de forma interativa, acaba criando o processo de inovação, que permite intensas relações entre agentes distintos, o que, por sua vez, exige novos formatos organizacionais em rede (LEMOS, 1999), inclusive com o aparelhamento das instituições.

Martins (2001) faz lembrar que a abordagem neoschumpeteriana fundamenta-se na noção do learning by interacting, considerada fundamental quando se concebe o território com base em três categorias: as redes de empresas, os sistemas de inovação e a eficiência coletiva.

Afirma Martins (2001, p. 79):

a análise neoschumpeteriana das redes de empresa enfatiza os aspectos dinâmicos desses arranjos, em termos de aglutinação de competências para realizar a inovação. Já a noção de sistemas de inovação [...] coloca a ênfase na interação entre os diversos agentes presentes em um território, o que evidencia um grau de territorialização maior. A terceira noção analisada, a de Eficiência Coletiva, enfatiza as economias externas geradas pela clusterização, e a ação coletiva deliberadamente realizada pelas empresas do cluster.

A importância do território na abordagem neoschumpeteriana tem sido enfatizada nas discussões mais recentes sobre desenvolvimento, pois o território - e, por extensão, a dimensão local - permite que se tenha uma compreensão melhor dos processos inovadores potencialmente geradores de desenvolvimento local, principalmente quando tal espaço tem a capacidade de criação de um ambiente inovador.

De modo mais geral, pode-se dizer que os efeitos gerados localmente a partir dos resultados obtidos com a inovação, em virtude principalmente da forma como está organizado o território e como se dá a relação entre os agentes econômicos, portanto, em virtude de aspectos socioinstitucionais, podem ser estendidos à coletividade, lançando-se as bases para que o processo de geração e de incorporação de inovações promova, de fato, o progresso econômico.

Entretanto, é importante destacar que, no caso de regiões localizadas à margem dos centros mais evoluídos em termos de processos técnico-econômicos, em razão principalmente do grau de dificuldade existente e do hiato técnico presente, as ações dos agentes econômicos estabelecidos localmente contribuem decisivamente para a formação de um ambiente propício ao desenvolvimento de mecanismos que possam inserir essas regiões no mundo globalizado e fazê-las competir em condições, se possível, de igualdade. 
Isso leva a constatar que, embora as mudanças técnicas hodiernas tenham avançado no sentido de tornar os diversos ambientes mais próximos, por meio da incorporação de espaços econômicos marginais, não necessariamente os tornaram menos desiguais social e territorialmente. Dessa forma, o local tem extrema importância na inserção no mundo globalizado (ALBAGLI; MACIEL, 2004).

Foi o que se observou no município de Vigia de Nazaré (PA). São evidentes os efeitos locais do progresso industrial do setor pesqueiro e da conseqüente geração e incorporação de inovações. As instituições locais e as instituições externas que atuam localmente têm participado desse progresso e, ao mesmo tempo, têm sido influenciadas pela conduta desse setor, adotando políticas e mecanismos que atingem os demais agentes da atividade municipal e promovendo a criação de um ambiente mais favorável ao desenvolvimento sustentado da pesca.

As instituições, portanto, investem na interação humana, do ponto de vista político, social ou econômico (NORTH, 1998), porque são moldadas pela interação que existe entre os indivíduos e, ao mesmo tempo, são resultado dessa interação. Assim sendo, as instituições precisam acompanhar o processo evolutivo das economias nacionais, regionais e locais para criar um ambiente favorável às interações, pois as performances alcançadas por estas economias devem-se à natureza de suas instituições e à sua capacidade de inovar (AREND; CÁRIO, 2005). É a partir do processo inovador que se modificam as instituições, tentando criar um ambiente capaz de promover o desenvolvimento econômico, pois "as mudanças institucionais, assim como as tecnológicas, devem ser compreendidas como um processo evolucionário" (NELSON, 2006, p. 12).

\section{INOVAÇÃO, MUDANÇAS INSTITUCIONAIS E IMPORTÂNCIA ECONÔMICA E SOCIAL DA PESCA DO MUNICÍPIO DE VIGIA DE NAZARÉ (PA)}

A atividade pesqueira é uma importante atividade econômica no Norte brasileiro, no âmbito tanto regional, quanto estadual e local. No caso do município de Vigia de Nazaré, localizado a 96 km de Belém, capital do Estado do Pará, a pesca é responsável praticamente pelo funcionamento da economia do município, principalmente em seu aspecto formal.

No município de Vigia de Nazaré, a pesca tem uma estrutura bipolar, com predominância, em termos quantitativos, do setor artesanal, o qual é responsável pelo maior volume de produção e de ocupações. É importante destacar que nesse segmento existe um predomínio da informalidade: aproximadamente $80 \%$ do total das ocupações e dos estabelecimentos ligados à pesca estão enquadrados nesse tipo de relação econômica.

Apesar de sua importância para a economia local, o setor artesanal é pouco dinâmico e contribui infimamente para o desenvolvimento da 
atividade pesqueira, que depende do desempenho do setor industrial ali estabelecido. De fato, o setor industrial pesqueiro vigiense ${ }^{3}$ é o mais dinâmico em seu segmento, em âmbito tanto local quanto estadual e até regional. Graças às práticas inovadoras adotadas, o setor industrial pesqueiro imprime um novo ritmo de desenvolvimento ao local.

O setor industrial pesqueiro é também responsável praticamente pela totalidade da indústria no município, assim como responde por uma parte significativa dos empregos formais locais (em 2006 foram registrados 545 empregos na indústria de pesca, o que corresponde a $30,1 \%$ do total de empregos formais do município). Por isso, Vigia de Nazaré é o município paraense mais especializado na atividade pesqueira nos últimos anos (ver Tabela 1).

Tabela 1: Participação do emprego formal da indústria pesqueira vigiense nos demais setores da economia (2000/2006).

\begin{tabular}{c|c|c|c}
\hline Ano & Indústria pesqueira (A) & Município (B) & $\mathrm{A} / \mathrm{B}$ \\
\hline 2000 & 172 & 1.016 & 16,93 \\
2001 & 249 & 1.178 & 21,14 \\
2002 & 275 & 1.132 & 24,29 \\
2003 & 370 & 1.280 & 28,91 \\
2004 & 481 & 1.300 & 37,00 \\
2005 & 498 & 1.688 & 29,50 \\
2006 & 545 & 1.809 & 30,13 \\
\hline
\end{tabular}

Fonte: BRASIL, 2008.

A posição de Vigia de Nazaré deve-se ao grau de formalidade que existe no setor industrial pesqueiro, tanto localmente quanto em relação ao restante do Estado. É realmente considerável a participação dos empregos gerados formalmente pela indústria de pesca no âmbito tanto local, quanto estadual. Analisando especificamente o estoque de empregos da indústria local, constata-se que, na série analisada, um crescimento continuado. Isso corrobora a situação do setor pesqueiro industrial vigiense, o qual tem apresentado desempenho progressivo no mercado de seu segmento (SANTOS; CRUZ, 2006), ao mesmo tempo que promove mudanças nunca observadas até então na estrutura institucional.

O total de empregos formais do município também tem registrado crescimento. Nos últimos três biênios, houve uma elevação, mas o maior índice (29,85\%) foi registrado no biênio 2004/2005, período em que o setor industrial local sofreu maior dinamização. No período de 2005 a

\footnotetext{
${ }^{3}$ Como se busca analisar os efeitos causados formalmente na economia vigiense, optou-se por pesquisar as empresas que se encontram formalmente estabelecidas e que também processam o peixe, transformando-o em produto final. No caso específico do município de Vigia de Nazaré, duas empresas preenchiam essas condições; por isso, foram as únicas consideradas por este estudo.
} 
2006, o crescimento foi da ordem de 7\%, praticamente todo gerado pelo setor industrial. Houve um maior dinamismo econômico, e a nova postura da indústria pesqueira produziu resultados positivos na economia vigiense.

No âmbito do Estado, considerando-se isoladamente o setor industrial da pesca, Vigia de Nazaré responde por elevada parte dos empregos formais. Em 2004, por exemplo, respondeu por nada menos que 45,59\% do total do Pará (ver Tabela 2).

Tabela 2: Participação da indústria da pesca vigiense no emprego formal do setor no Estado do Pará (2000/2006).

\begin{tabular}{c|c|c|c}
\hline Ano & Vigia (A) & Pará (B) & A/B \\
\hline 2000 & 172 & 748 & 22,99 \\
2001 & 249 & 1.307 & 19,05 \\
2002 & 275 & 1.157 & 23,77 \\
2003 & 370 & 840 & 44,05 \\
2004 & 481 & 1.055 & 45,59 \\
2005 & 498 & 1.151 & 43,27 \\
2006 & 545 & 1.386 & 39,32 \\
\hline
\end{tabular}

Fonte: BRASIL, 2008.

Em 2006, houve uma queda relativa na participação do emprego formal da pesca industrial de Vigia de Nazaré em relação ao total do Estado, fato que pode ser resultado das ações governamentais, principalmente das ações federais, que aumentaram o número de empregos da pesca industrial no Pará - o índice de crescimento foi da ordem de $20 \%$.

Constata-se, entretanto, que, no Estado como um todo, o setor apresenta um baixo nível de empregos formais quando comparado a outros setores da economia, o que decorre principalmente do baixo dinamismo de grande parte das empresas que o compõem.

Além de sua capacidade de agregar grande parte dos postos de trabalho, a pesca industrial de Vigia de Nazaré assume um papel de destaque no cenário regional e estadual graças à postura adotada a partir de 1998, quando o setor apostou na inovação para alcançar um novo estágio e status em seu segmento. O grau de desenvolvimento alcançado desde então é promissor e idiossincrático, o que torna o município o centro de atenção de políticas voltadas para o desenvolvimento sustentado da pesca, ao mesmo tempo que se forma no espaço local uma nova estrutura institucional que busca criar um ambiente favorável à extensão de externalidades positivas geradas por esse novo momento da pesca industrial vigiense.

O desempenho apresentado pelo setor tem induzido a formação de um arranjo institucional robusto em sua composição e, pelo menos em termos de propostas, e a adoção de políticas que dão impulso e sustentação à atividade no município, proporcionando-lhe uma nova configuração (ver Figura 1). 


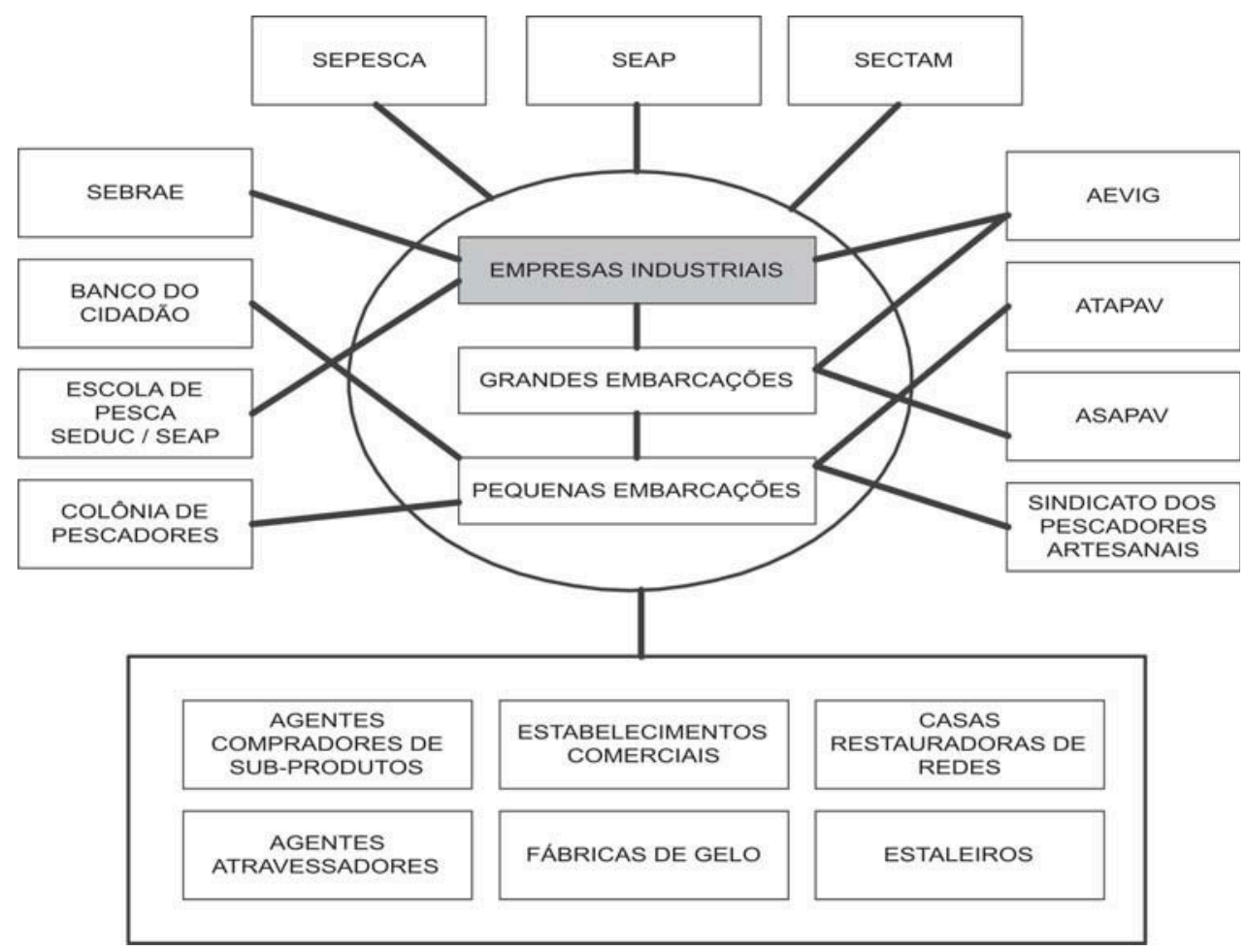

Figura 1: Configuração do APL(i) Pesca do município de Vigia de Nazaré (PA).

Fonte: Santos, 2007.

A postura do setor industrial pesqueiro vigiense e os efeitos causados retrospectivamente e prospectivamente (HIRSCHMAN, 1985) - embora os últimos ainda sejam modestos localmente - provocaram a formação de um novo arranjo institucional capaz de atender as necessidades surgidas com as mudanças técnicas implementadas. Assim, desde 2004, o município vive um momento muito particular, porque o poder público local criou uma secretaria específica (Secretaria de Pesca e Agricultura (SEPESCA)) a fim de dar suporte ao setor como um todo; em 2005 e 2006, o Governo Federal (SEBRAE e SEAP) e o Estadual (SAGRI, SEDUC e Banco do Cidadão) instalaram unidades institucionais no local, ao mesmo tempo que passaram a implementar políticas públicas específicas, destinadas a estender as externalidades positivas geradas localmente aos demais agentes econômicos diretamente ligados à atividade.

É importante destacar que esse estágio alcançado pela pesca industrial é fruto também da capacidade dos empresários instalados no município de Vigia de Nazaré, que seguem as lições inovadoras de Schumpeter na condução do processo de desenvolvimento do setor. Existe localmente uma empresa que inova rotineiramente e assume a liderança na pesca, diferenciando-se de todas as outras estabelecidas no arranjo e fora dele, no Estado e na região. 
Conforme é mostrado no quadro abaixo, inovações são feitas com freqüência, no que diz respeito ao produto e ao processo, na esfera comercial e na esfera organizacional. Isso reforça a posição assumida pelo município de Vigia de Nazaré como foco de atenção das instituições responsáveis pelas políticas públicas para a pesca. Destacam-se, particularmente, as inovações referentes a produtos, os quais, embora possam existir em algum outro local (externo à região Norte), são cruciais e projetam o setor para um novo estágio de desenvolvimento, ao mesmo tempo que reduzem a pressão sobre o meio ambiente, promovendo um desenvolvimento sustentável e sustentado da atividade.

\begin{tabular}{|c|c|c|}
\hline Des & Sim & Não \\
\hline \multicolumn{3}{|l|}{ Inovação de produto } \\
\hline \multirow{2}{*}{$\begin{array}{l}\text { Produto novo ou significativamente aprimorado pela empresa, } \\
\text { mas já existente no setor? }\end{array}$} & 2 & \\
\hline & $100,00 \%$ & 0,00 \\
\hline \multirow{2}{*}{ Produto novo ou significativamente aprimorado para o setor? } & & \\
\hline & $50,00 \%$ & 50,00 \\
\hline \multirow{2}{*}{$\begin{array}{l}\text { Produto novo ou significativamente aprimorado para o mercado } \\
\text { nacional e/ou internacional? }\end{array}$} & & \\
\hline & $50,00 \%$ & $50,00 \%$ \\
\hline \multicolumn{3}{|l|}{ Inovação de processos } \\
\hline \multirow{2}{*}{$\begin{array}{l}\text { Processo novo ou tecnicamente aprimorado para a empresa, mas } \\
\text { já existente no setor? }\end{array}$} & 2 & \\
\hline & $100,00 \%$ & $0,00 \%$ \\
\hline \multirow{2}{*}{ Processo novo ou tecnicamente aprimorado para o setor? } & & \\
\hline & $50,00 \%$ & $50,00 \%$ \\
\hline \multirow{2}{*}{$\begin{array}{l}\text { Processo novo ou tecnicamente aprimorado para o mercado } \\
\text { nacional e/ou internacional? }\end{array}$} & & \\
\hline & $50,00 \%$ & $50,00 \%$ \\
\hline \multicolumn{3}{|l|}{ Inovação comercial } \\
\hline \multirow{2}{*}{$\begin{array}{l}\text { Realização de significativa mudança no desenho ou na } \\
\text { embalagem do produto? }\end{array}$} & 2 & \\
\hline & $100,00 \%$ & $0,00 \%$ \\
\hline \multirow{2}{*}{$\begin{array}{l}\text { Adoção de novas técnicas de colocação do produto no mercado } \\
\text { (novos canais de venda)? }\end{array}$} & 0 & \\
\hline & $0,00 \%$ & $100,00 \%$ \\
\hline \multirow{2}{*}{$\begin{array}{l}\text { Adoção de novas técnicas de promoção do produto (marketing), } \\
\text { como divulgação em mídia, introdução de uma nova marca no }\end{array}$} & & \\
\hline & $50,00 \%$ & $50,00 \%$ \\
\hline \multirow{2}{*}{$\begin{array}{l}\text { Adoção de novas estratégias de preço para o mercado do } \\
\text { produto da empresa? }\end{array}$} & & \\
\hline & $100,00 \%$ & $0,00 \%$ \\
\hline \multicolumn{3}{|l|}{ Inovação organizacional } \\
\hline \multirow{2}{*}{$\begin{array}{l}\text { Adoção de novas práticas de gestão, inclusive para a melhoria do } \\
\text { aprendizado e o compartilhamento do conhecimento dentro da }\end{array}$} & 2 & \\
\hline & $100,00 \%$ & $0,00 \%$ \\
\hline \multirow{2}{*}{$\begin{array}{l}\text { Realização de significativas mudanças na estrutura } \\
\text { organizacional, com a adocão de novos métodos para a }\end{array}$} & & \\
\hline & $50,00 \%$ & $50,00 \%$ \\
\hline \multirow{2}{*}{$\begin{array}{l}\text { Adoção de novos métodos de relações externas da empresa e de } \\
\text { novas formas de colaboração com instituições de pesquisa ou }\end{array}$} & & \\
\hline & $100,00 \%$ & $0,00 \%$ \\
\hline \multirow{2}{*}{$\begin{array}{l}\text { Adoção de novos métodos de integração com fornecedores, } \\
\text { subcontratados ou terceirizados, envolvendo produtos/serviços }\end{array}$} & & \\
\hline & $100,00 \%$ & $100,00 \%$ \\
\hline \multirow{2}{*}{$\begin{array}{l}\text { Adoção de novos métodos de controle e de gerenciamento } \\
\text { visando atender normas de certificacão (ISO9000, ISO14000, }\end{array}$} & & \\
\hline & $50,00 \%$ & $50,00 \%$ \\
\hline
\end{tabular}

Quadro 1: Inovações adotadas pelas empresas no período de 2000-2005. Fonte: Santos, 2007. Adaptado com base no questionário da REDESIST. 
Examinando-se o setor no Estado do Pará, observa-se que, embora as empresas estejam concentradas mais perto dos centros de desenvolvimento de pesquisas, as inovações restringem-se à melhoria de produtos já existentes para fins de adequação às exigências do mercado. Portanto, limitam-se às chamadas inovações de processos e pouco contribuem para o desenvolvimento do setor.

Com o intuito de reforçar a posição de destaque e para melhor entender o que diferencia o setor pesqueiro industrial de Vigia de Nazaré do restante do Estado, optou-se por pesquisar e analisar algumas das empresas do setor, aquelas com maior representatividade dentro do Pará. Assim sendo, foram quatro as empresas pesquisadas ${ }^{4}$.

Procurou-se examinar principalmente as inovações adotadas nos últimos anos e questionar a finalidade dessas inovações. Verificou-se que várias foram as ações realizadas, variando de processos a produtos, na relação com a produção do pescado, entretanto, nenhuma de caráter radical. Basicamente todas as ações inovadoras foram de caráter incremental.

Todas as empresas que responderam ao questionário informaram ter realizado inovações quanto a produtos, embora tenham sido melhorias significativas, como, por exemplo, adequação de tamanho e embalagem. Nenhuma das empresas entrevistadas lançou produtos novos no mercado; tampouco se constatou nas empresas a presença do setor de P\& D ou o desenvolvimento de atividades inovadoras. Todas as inovações adotadas para o produto foram, portanto, importadas do mercado em sua totalidade, e a principal estratégia é o atendimento do mercado com qualidade e eficiência ${ }^{5}$.

Quando indagadas a respeito de inovações de processos, todas as empresas mostraram-se preocupadas com a questão do enquadramento nas normas de qualidade exigidas pelo mercado. Todas as empresas responderam que têm um centro de controle da qualidade e que constantemente inovam nesse departamento. Destarte, pode-se afirmar que a inovação inaugura um novo momento para a economia vigiense porque, ao mesmo tempo que promove mudanças na principal atividade econômica local, gera efeitos para toda a economia, principalmente aumentando a participação do setor na geração de emprego e renda formal, fazendo de Vigia de Nazaré o principal centro dinamizador da pesca no Estado.

\footnotetext{
${ }^{4}$ A escolha de apenas quatro das empresas que atuam no setor industrial da pesca do Pará deve-se principalmente às similitudes, no que diz respeito à postura e ao setor, entre elas e a empresa líder do setor no município de Vigia de Nazaré.

${ }^{5}$ Aqui o termo "eficiência" expressa a adequação dos produtos às exigências de seus consumidores/clientes.
} 
Portanto, no caso específico de Vigia de Nazaré, a evolução técnica está promovendo melhorias econômicas e sociais locais e, ao mesmo tempo, transformando o arcabouço institucional existente a fim de incrementar o desenvolvimento local.

Assim sendo, a inovação reforça seu caráter de força motriz do desenvolvimento econômico, proporcionando a Vigia de Nazaré uma nova dinâmica econômica e social. Isso leva-nos a refletir sobre as condições endógenas do desenvolvimento. Para Barquero (2001) e Boisier (2005), transformações de caráter econômico, organizacional, tecnológico, político e institucional são decorrentes do comportamento dos atores locais e da utilização eficiente dos recursos disponíveis. Boisier (2005) destaca a participação dos atores e dos recursos locais no processo de globalização. Portanto, a capacidade de organização social do ambiente é essencial para o desenvolvimento endógeno. Entretanto, é válido lembrar que, em Vigia de Nazaré, sobressai o desempenho basicamente de um agente líder: uma empresa de pesca industrial.

\section{CONSIDERAÇÕES FINAIS}

O desenvolvimento de produtos e processos passou a fazer parte da rotina da empresa líder do setor industrial da pesca no município de Vigia de Nazaré. Embora tenha sido iniciado por provocações do mercado internacional - para atender uma exigência em um processo de interação parcial -, passou a ser o resultado de uma política de atuação empresarial.

Desse modo, um novo cenário formou-se no segmento da pesca como um todo, de modo mais particular e mais dinâmico no setor industrial. Novos produtos e processos foram adotados, o que causou impactos positivos sobre a força de trabalho e o meio ambiente.

A adoção de inovações trouxe maior capacidade de competição do setor no mercado, elevando o volume de absorção de mão-de-obra e aumentando a renda do trabalho direta e indiretamente. Quanto ao meio ambiente, constata-se uma redução do chamado esforço de pesca e dos resíduos, que antes eram devolvidos ao rio. Espécies de baixo valor comercial passaram também a ser aproveitadas, o que gerou um equilíbrio (ou reduziu o déficit) na captura de espécies de maior valor.

Dado esse desempenho e a transformação do município em pólo inovador e promissor regional, o setor público, em âmbito tanto local quanto estadual e nacional, passou a querer consolidar ali uma espécie de modelo promotor de desenvolvimento. Daí a formação de um novo arranjo institucional, o que fortaleceu as poucas instituições que estavam estabelecidas no local.

Criou-se um ambiente favorável à promoção do desenvolvimento. Mas, ressalte-se, é preciso que se adotem políticas que visem atingir 
todo o setor e sua cadeia produtiva, sem que haja isolamento de quaisquer etapas, no intuito de se evitar o favorecimento e o fortalecimento de fragmentos que ponham em risco o processo ali estabelecido.

As instituições precisam criar mecanismos que fortaleçam o setor pesqueiro vigiense, para torná-lo mais dinâmico e competitivo. Para isso, é preciso que o arranjo institucional que ali se estabelece ultrapasse os limites de sua condição física, presencial e estatutária e atue efetivamente.

É provável que dessa forma haja uma maior mobilidade dos atores locais envolvidos direta e indiretamente na pesca. Só assim se garantiria a sustentabilidade da atividade e se estimularia o estabelecimento de empresas naquele espaço. 


\section{REFERÊNCIAS}

ALBAGLI, S.; MACIEL, M. L. Informação e conhecimento na inovação e no desenvolvimento local. Ciência da Informação, Brasília, DF, v. 33, n. 3, p. 9-16, set./dez. 2004.

AREND, M.; CÁRIO, S. A. F. Instituições, inovações e desenvolvimento econômico. Florianópolis: UFSC, 2005.

BARQUERO, A. V. Desenvolvimento endógeno em tempos de globalização. Porto Alegre: Fundação de Economia e Estatística, 2001.

BOISIER, S. Hay espacio para el desarrollo local en la globalización? Revista de la CEPAL, Santiago, n. 86, p. 47-62 ago. 2005.

BRASIL. Ministério do Trabalho e Emprego. Relatório Anual de Informações Sociais (RAIS). Disponível em: <http://www.mte.gov.br/ rais>. Acesso em: 16 jan. 2008.

CROCCO, M. A. et al. Metodologia de identificação de arranjos produtivos locais potenciais. Nova Economia, Belo Horizonte, v. 16, n. 2, p. 211241, maio/ago. 2006.

DOSI, G. Technical change and industrial transformation: the theory and an application to the semiconductor industry. London: Macmillan, 1984.

GALVÃO. A. P. O desenvolvimento local e a dimensão social da inovação. Rio de Janeiro: LABTeC/EPPG/UFRJ, 2002.

HIRSCHMAN, O. Desenvolvimento por efeitos em cadeia: uma abordagem generalizada. In: CARDOSO, F. H.; SORJ, B.; FONT, M. (Org.). Economia e movimentos sociais na América Latina. Rio de Janeiro: Brasiliense, p. 31-79, 1985.

KUPFER, D. Uma abordagem neo-schumpeteriana da competitividade industrial. Ensaios FEE, Rio de Janeiro, ano 17, n. 1, p. 355-372, 1996.

LALL, S. A mudança tecnológica e a industrialização nas economias de industrialização recente da Ásia: conquistas e desafios. In: KIM, L.; NELSON, R. Tecnologia, aprendizado e inovação: as experiências das economias de industrialização recente. Campinas: Unicamp, p. 25-99, 2005 . 
LASTRES, H. M. M. et al. Globalização e inovação localizada. In: LASTRES, H. M. M.; ALBAGLI, S. (Org.). Informação e globalização na era do conhecimento. Rio de Janeiro: Campus, p. 07-26, 1999.

LEMOS, C. Inovação na era do conhecimento. In: LASTRES, H. M. M.; ALBAGLI, S. (Org.). Informação e globalização na era do conhecimento. Rio de Janeiro: Campus, p. 122-144, 1999.

MARTINS, H. E. P. Transformações recentes na produção e no território: uma abordagem neoschumpeteriana. Rio de Janeiro: UFRJ/IPPUR, 2001.

NELSON, R. R. As fontes do crescimento econômico. Campinas: Unicamp, 2006.

NELSON, R. R.; WINTER, S. Uma teoria evolucionária da mudança econômica. Campinas: Unicamp, 2005.

NORTH, D. C. Custos de transação, instituições e desempenho econômico. Rio de Janeiro: Instituto Liberal, 1998.

PAULA, J. A. et al. Ciência e tecnologia na dinâmica capitalista: a elaboração neo-schumpeteriana e a teoria do capital. Belo Horizonte: UFMG/CEDEPLAR, 2001.

PAVITT, K. Sectoral patterns of technical change. Research policy, Oslo, n. 13, p. 343-373, 1984.

POSSAS, M. Em direção a um paradigma microdinâmico: a abordagem neoschumpeteriana. In: AMADEO, E. (Org.) Ensaios sobre economia política moderna. São Paulo: Marco Zero, p. 157-177, 1989.

ROSENBERG, N. Perspectives on technology. Cambridge: Cambridge University, 1976.

ROSENBERG. N. Por dentro da caixa preta: tecnologia e economia. Campinas: Unicamp, 2006.

SANTOS, J. N. A. Industrialização e inovação no setor pesqueiro vigiense: análise sobre as possíveis contribuições para o desenvolvimento local. 2007. 149 f. Dissertação (Mestrado em Planejamento do Desenvolvimento) - Núcleo de Altos Estudos Amazônicos, Universidade Federal do Pará, Belém, 2007. 
SANTOS, J. N. A.; CRUZ, A. G. Arranjo produtivo local da pesca: contribuições e possibilidades de uma nova etapa no ambiente econômico e institucional de Vigia de Nazaré - Pará. In: ENCONTRO NACIONAL DA ASSOCIAÇÃO BRASILEIRA DE ESTUDOS REGIONAIS, 4., 2006, FoZ do Iguaçu. Anais... Foz do Iguaçu, out. p. 01-18, 2006.

TAPIA, N.; CAPDEVIELLE, A. Corrientes y conceptos de la teoría evolucionista. In: TREVIÑNO, L. C. Teorías económicas de la innovación tecnológica. Ciudad del México: Escola Superior de Economia, p. 212230, 2002 .

TEECE, D. J. As aptidões das empresas e o desenvolvimento econômico: implicações para as economias de industrialização recente. In: KIM, L.; NELSON, R. Tecnologia, aprendizado e inovação: as experiências das economias de industrialização recente. Campinas: Unicamp, p. 147-178, 2005 .

TREVIÑO, L. C. Teorías económicas de la innovación tecnológica. Ciudad del México: Escola Superior de Economia, 2002. 